\title{
Utilization of sweet kalina lupin seed by the weaned piglet Effect of the incorporation level and the physical form
}

\author{
P. QUEMERE *, J. FEKETE **, M. LEUILLET **, F. WILLEQUET * \\ * S.E.R.E.P., Institut Supérieur agricole, 60026 Beauvais \\ *: I.T.C.F., 8, avenue du Président-Wilson, 75116 Paris \\ France
}

In a first trial involving 336 crossbred piglets we compared four experimental diets based on wheat and soyabean meal, containing $0,3,6$ and 9 p. 100 lupin and offered as pellets.

In a second trial concerning 400 crossbred piglets we tested the effect of incorporation of 10 p. 100 lupin in diets offered either as flour or as pellets. In these trials weaned piglets weighed 7.9 and $7.5 \mathrm{~kg}$ and had the mean age of 27.7 and 28.3 days, respectively.

They were fed ad libitum for two weeks, the first age diet already used before weaning, then for 28 days the experimental diets $(25.7$ and $21.9 \mathrm{~kg})$.

The results of the first trial showed that the decrease in the feed intake was only significantly marked at the highest level of incorporation and during the first two weeks of experiment. The feed efficiency of diets containing lupin was reduced by 6 p. 100 as compared to the diet without lupin. The results of the second trial showed that the improvement of the feed efficiency obtained by pelleting was similar with and without lupin. This improvement corresponded to that observed in former studies.

Conversely, the presence of Iupin led to a decrease in the feed intake of nearly $10 \mathrm{p} .100$ and of the growth rate of 6 to $7 \mathrm{p}$. 100 . This confirms our results of 1982 and allows to conclude that the use of lupin in second age diets is not advisable.

\author{
Utilization of "simple 0 " rapeseed oil-meal by the bacon pig \\ F. GROSJEAN, O. LAVOREL \\ I.T.C.F., 8, avenue du Président-Wilson, 75116 Paris \\ France
}

Four diets based on wheat and soyabean meal including 0 p. 100, 3 p. 100, 6 p. 100, 9 p. 100 of "simple 0 » rapeseed oilmeal were compared in a trial involving 96 bacon pigs between 28.5 and $100.3 \mathrm{~kg}$. Diets were formulated on the basis of the same lysine/DE ratio of $2.7 \mathrm{~g} / 100 \mathrm{Kcal}$. They were offered restricted as moistened meal at the through. «Simple 0 » rapeseed oilmeal was prepared with grains free of erucic acid, but with rather large glucosinolate contents. As compared to the other varieties usually produced in France containing 2.0 to $4 \mathrm{mg} \mathrm{ITC/g} \mathrm{DM}$ and 7.0 to $0.9 \mathrm{mg} \mathrm{TOV} / \mathrm{g} \mathrm{DM}$, its quality was very good due to very low ITC and TOV contents $(1.65 \mathrm{mg} / \mathrm{g}$ DM and $5.22 \mathrm{mg} / \mathrm{g} \mathrm{DM}$, respectively).

The levels of feed intake corresponded to the feed restriction plan. Growth rates and feed conversion ratios were the same whatever the diet. Carcass yield decreased almost linearly with increased levels of incorporation of rapeseed oil-meal into the diet (about 0.5 point per point of oil-meal). The lean percentage was not significantly affected by the presence of rapeseed oil-meal in the diet. 